\title{
States of Water in Proton Exchange Membranes: Part A - Influence of Chemical Structure and Composition
}

\author{
Abhishek Roy, ${ }^{1 i}$ Michael A. Hickner, ${ }^{2}$ Hae-Seung Lee, ${ }^{1}$ Tom Glass, ${ }^{1}$ \\ Mou Paul, ${ }^{1 i}$ Anand Badami, ${ }^{1}$ Judy S. Riffle ${ }^{1 *}$ and James E. McGrath ${ }^{1}$
}

\begin{abstract}
\end{abstract}
Disulfonated poly(arylene ether) and polyimide copolymers can phase separate to form nano-scale hydrophilic and hydrophobic domain morphology. Water in these domains has been assigned to three different states, tightly bound, loosely bound and free water. The states of water were characterized using DSC, NMR relaxation and TGA. The chemical structures of the proton exchange membranes were varied in chemical composition, microstructure (random and block) and also regarding functional sulfonic acid groups fixed to the polymer backbones. A strong dependence of the types of water on the ion content and morphology was observed. For the random copolymers, the formation of free water in the system occurs after reaching a certain ion content. For the multi-blocks, in addition to the ion content, free water also develops with increasing block lengths. The formation of continuous morphology in the copolymers was correlated to the onset 
of free water. Influences of the states of water on PEM transport properties will be reported separately.

\section{Introduction}

Fuel cells are electrochemical devices that convert chemical energy to electrical energy [1]. Among various types of fuel cells, proton exchange membrane fuel cells (PEMFCs) are of major importance. PEMFCs have a diverse field of applications ranging from stationary, automotive to even portable power systems. Hydrogen-air fuel cells and direct methanol fuel cells (DMFCs) are the two main types used for these applications $[2,3]$. Typical operating principles for a PEMFC involve oxidation of the $\mathrm{H}_{2}$ fuel at the anode to form positively charged hydrogen ions and electrons. The hydrogen ions (protons) are transported across the proton exchange membrane (PEM) to the cathode where they combine with the electrons and react with oxygen to form water. The integral part of the fuel cell is considered to be the PEM and its primary demands are high proton conductivity and low water uptake. In addition, the membrane should have both thermal and oxidative stability, good mechanical properties, low permeability to fuels and dimensional stability under hydrated conditions $[4,5]$. The current state of the art PEMs are perfluorosulfonic acid membranes such as Nafion ${ }^{\circledR}$ manufactured by DuPont. These membranes show excellent chemical and electrochemical stability as well as high proton conductivity with relatively low water uptake on a mass basis. However, Nafion ${ }^{\circledR}$ suffers from disadvantages including high cost, high methanol permeability (DMFCs), and limited operating temperature $\left(\sim 80^{\circ} \mathrm{C}\right)[5,6]$ due to its low hydrated $\alpha$ relaxation temperature [7]. Our research group has been engaged in the past few years in the synthesis and characterization of biphenol based partially disulfonated poly(arylene ether sulfone) (BPSH) random copolymers as potential PEMs [4, 8-12]. 
All of these sulfonated copolymers phase separate to form nanoscale hydrophilic and hydrophobic morphological domains. The hydrophilic segments containing the sulfonic acid moieties cause the copolymer to absorb water. Water confined in hydrophilic domains in concert with the sulfonic acid groups serve the critical function of proton (ion) conduction in these systems [13]. Transport of water and protons in these confined systems are of both fundamental interest and technological importance in the design of new materials. There are multiple states of water that have been associated with water residing in hydrophilic phases of polymers [14-17]. These states can be defined by thermal properties. While it is reasonable that the states of water effectively represent regions within a continuum, except for the bulk-like water, they are approximated as three different states herein for illustrative purposes. Non-freezing bound water has been attributed to that being strongly associated with the polymer. It depresses the polymer $\mathrm{T}_{\mathrm{g}}$, but this water shows no melting endotherm by differential scanning calorimetry (DSC). Freezable bound water may be weakly bound to the polymer (or weakly bound to the non-freezing water), and it has been characterized as displaying broad melting behavior around and slightly below 0 ${ }^{\circ} \mathrm{C}$. Finally, water that exhibits a sharp melting point at $0{ }^{\circ} \mathrm{C}$ has been designated as free water.

The states of water in hydrophilic polymers have been characterized by various methods including DSC and NMR relaxation measurements [14, 15, 18-26]. Mendil-Jakani et al. utilized DSC to study the nature of water in $\mathrm{Nafion}{ }^{\circledR}$ and compared this to water in a disulfonated polyimide that had very short block sequences (average five disulfonated units in a multi-block with five non-sulfonated repeat units) [22]. They showed that water does not crystallize in Nafion ${ }^{\circledR}$ until very high water compositions are reached, and this transition to allow crystallization was postulated to be related to a domain size for the water of about $5 \mathrm{~nm}$. Water inside the block 
copolyimide behaved quite differently. It neither crystallized nor desorbed even at large interdomain distances of $\sim 25 \mathrm{~nm}$. This was attributed to a different internal structure of the aqueous domains together with much stronger polymer-water interactions along the polyimide backbone relative to Nafion ${ }^{\circledR}$. Previous work on disulfonated polysulfones based on biphenol has shown that DSC thermograms are descriptive of water content in those polymers, showing melting endotherms of loosely bound and free water [15]. Tightly bound water was correlated to the amount of absorbed water for which there was no melting endotherm. Quinn et al. [14] proposed a mathematical technique to estimate the amount of tightly bound water. They suggested that if the integrated change in enthalpy of fusion of the water (per gram of dry polymer) from the DSC thermogram is plotted against water content, the intercept gives the tightly bound water content. Then by subtracting the tightly bound water from the total water, the combined content of any loosely bound and free water was obtained. However, it is difficult to distinguish or quantify freezable loosely bound and free water separately using DSC since the two melting endotherms corresponding to free and loosely bound water overlap.

NMR relaxation $\left(T_{2}\right)$ experiments can shed light on the states of water as reported by Whittaker et al. for a set of hydrogel materials [18]. They reported that for a hydrophilic polymer that contains water in three states, the decay in the transverse magnetization of water protons could be modeled to a tri-exponential function. The shortest time component of the decay with the fastest relaxation rate was attributed to tightly bound water having the shortest diffusive path length. The intermediate component was attributed to loosely bound water and the long time component of the $\mathrm{T}_{2}$ decay (slow $\mathrm{T}_{2}$ relaxation) was related to the bulk or free water. The relative fractions of the 
coefficients of the exponential terms were designated as being proportional to the respective types of water, thus allowing quantification of each.

This paper (Part A) characterizes the water in sulfonic acid containing PEMs using DSC, TGA and NMR relaxation measurements. The influence of the distribution of the types of water on various transport and electrochemical properties of the PEMs will be discussed in Part B. A controlled series of materials varying in ion content, chemical composition and sequence lengths has been prepared [Fig. 1], and structure-property relationships correlating these variables with the types of water absorbed in the polymers are described. The chemical microstructure was varied from a random arrangement of ionic groups to a phase separated multi-block morphology and both linear and crosslinked topologies have been considered. We show that the microstructure, and hence the morphology, correlates strongly with the characteristics of the water. Influences of the phase structures of the polymers as well as interactions between the functional groups on the polymers and the water molecules are discussed.

\section{Experimental}

\subsection{Materials}

Monomer grade 4,4'-dichlorodiphenylsulfone (DCDPS) was provided by Solvay Advanced Polymers. Hydroquinone (HQ) was obtained from Eastman Chemical Company. 4,4'Hexafluoroisopropylidenediphenol (6F-BPA), received from Ciba, was purified by sublimation. The ketone monomer, 4,4'-difluorobenzophenone (DFBP) was purchased from Aldrich and used as received. All of these monomers were dried under vacuum prior to use. The disulfonated comonomers, 3,3'-disulfonate-4,4'-dichlorodiphenylsulfone (SDCDPS) and 3,3'-disulfonate- 
4,4'-difluorobenzophenone (SDFBP), were synthesized according to modified literature methods [8] and dried under vacuum before copolymerization. The solvents $N, N$-dimethylacetamide (DMAc, Fisher) and $N$-methyl-2-pyrrolidinone (NMP, Fisher) were vacuum-distilled from calcium hydride onto molecular sieves. Potassium carbonate (Aldrich) was dried under vacuum before copolymerization. Toluene, sodium chloride, $30 \%$ fuming sulfuric acid and methanol were obtained from Aldrich and used as received. The fuming sulfuric acid was analyzed for active $\mathrm{SO}_{3}$ concentration [27]. Nafion ${ }^{\circledR} 112$ and 117 were obtained from ElectroChem, Inc.

\subsection{Synthesis of partially disulfonated poly(arylene ether) random copolymers (HQSH-xx and B-ketone-xx)}

Disulfonated poly(arylene ether sulfone) copolymers were synthesized via aromatic nucleophilic substitution as described previously [Fig. 1(a and b)] [8, 9, 28-32]. One typical reaction for a copolymer containing hydroquinone with $40 \%$ of the repeat units disulfonated (HQSH-40) is as follows. Hydroquinone (10 mmol), DCDPS (6 mmol), and SDCDPS (4 mmol) were charged to the flame dried 3-neck flask equipped with a mechanical stirrer, nitrogen inlet and a Dean-Stark trap. Potassium carbonate $(11.5 \mathrm{mmol})$ was added. Dry NMP was introduced to afford about a $20 \%$ solids concentration and toluene $(\mathrm{NMP} /$ toluene $=2 / 1 \mathrm{v} / \mathrm{v})$ was used as an azeotropic agent. The reaction mixture was placed in a silicone oil bath and heated under reflux at $150{ }^{\circ} \mathrm{C}$ for $4 \mathrm{~h}$ to remove the water and toluene. Then, the bath temperature was raised slowly to $180{ }^{\circ} \mathrm{C}$ and polymerization was continued for an additional $24 \mathrm{~h}$. The viscous solution was cooled to room temperature, and then diluted with NMP. The copolymer solution was filtered to 
remove the byproduct salt and then isolated by precipitation in deionized water. The copolymer was separated by filtration and dried in a vacuum oven at $120^{\circ} \mathrm{C}$ for $24 \mathrm{~h}$.

Copolymerization procedures for the poly(arylene ether ketone)s were similar to those for the polysulfones, although the monomer reactivities were different [29]. The B-ketone-xx series [Fig. 1(c)] copolymers were based on 6F-BPA, DFBP, and disulfonated difluorodiphenylsulfone (SDFBP). Because the fluorinated monomers have higher reactivity, high molecular weight copolymers were achieved within shorter reaction times.

\subsection{Synthesis of disulfonated poly(arylene ether sulfone)-b-polyimide (BPSH-x-PI-y)} multi-block copolymers [Fig. 1(d)]

A series of segmented disulfonated poly(arylene ether sulfone)-b-polyimide copolymers based on hydrophilic and hydrophobic oligomers was synthesized as previously described [33, 34]. The disulfonated hydrophilic oligomers were prepared from SDCDPS and biphenol and capped with $m$-aminophenol via step growth polymerization with different block lengths ranging from 5 to $20 \mathrm{~kg} / \mathrm{mole}$. Anhydride-terminated polyimide hydrophobic oligomers were prepared from naphthalene dianhydride and a novel amino-functional sulfone monomer. Anhydride endgroup functionality was achieved by adding stoichiometrically adjusted amounts of the monomers. Synthesis of the multi-block copolymers was facilitated by an imidization coupling reaction between the amine endgroups on the hydrophilic oligomers and the anhydride endgroups on the hydrophobic oligomers, thereby producing high molecular weight copolymers with alternating sequences of hydrophobic and hydrophilic prepolymers. 
2.4 Crosslinked disulfonated poly(arylene ether sulfone) random copolymers (BPSH$x-X X)$

BPS random copolymers varying in molecular weight and degree of disulfonation with terminal phenoxide or aromatic amine endgroups were synthesized $[35,36]$. The phenoxide or amine endgroups were then reacted with tetraglycidyl bis( $p$-aminophenyl)methane (Araldite MY721 epoxy resin) via ring-opening of the epoxide in the presence of triphenyl phosphine as a catalyst at $\sim 150{ }^{\circ} \mathrm{C}$ to form crosslinked membranes. Gel fractions that qualitatively represented the extent of crosslinking were varied from 10 to $80 \%$ by increasing the curing time of the phenoxide terminated oligomers.

\subsection{Membrane preparation}

The copolymers in their salt form were dissolved in DMAc to afford transparent 5 wt \% solutions, which were cast onto clean glass substrates. The films were slowly dried for 2 days with infrared heat at gradually increasing temperatures, and then dried under vacuum at $110{ }^{\circ} \mathrm{C}$ for 2 days. The membranes were converted to their acid form by boiling them in $0.5 \mathrm{M} \mathrm{H}_{2} \mathrm{SO}_{4}$ for $2 \mathrm{~h}$, and then they were boiled in deionized water for $2 \mathrm{~h}$ to remove any residual acid. The membranes were stored in deionized water until they were used for measurements.

2.6 Differential scanning calorimetry (DSC), nuclear magnetic resonance (NMR) and thermo-gravimetric analysis (TGA) 
DSC experiments were performed in a TA DSC instrument using liquid nitrogen as a cooling medium for sub-ambient operation. The samples were equilibrated in liquid water or in a controlled relative humidity oven (ESPEC SH240) to achieve the desired hydration levels. In some cases ionic salt solutions $(\mathrm{LiCl})$ were used to control the relative humidity. The samples were placed in sealed pans capable of withstanding a pressure of $100 \mathrm{~atm}$. Samples were cooled to -70 ${ }^{\circ} \mathrm{C}$ and then heated at a rate of $5{ }^{\circ} \mathrm{C}$ per min under a N2 atmosphere. The glass transition temperatures were extracted using the software as provided by the TA instrument (Universal V2.5 $\mathrm{H})$.

The proton spin-spin relaxation time, $\mathrm{T}_{2}$, was measured in a Varian Inova 400 spectrometer using a Carr-Purcell-Meiboom-Gill (CPMG) pulse sequence. The $90^{\circ}$ pulse was $13.8 \mu \mathrm{s}$ and the $180^{\circ}$ pulse was $27.6 \mu \mathrm{s}$. A total of 200 decay points were collected over $4 \mathrm{~ms}$. Samples were equilibrated at room temperature in water. Just before the experiment, they were removed from the water, blotted to remove surface water and placed in the NMR probe. The fitting procedure was performed using a non-negative least squares analysis by Matlab software. The quality of the fits was determined by comparing the statistical parameters (RMSE and SSE). The relative fractions of the coefficients of the exponential terms were assumed to be proportional to weighted averages of the respective types of water. The spin lattice relaxation time, $\mathrm{T}_{1}$, was measured using an inversion recovery method and sequence. The $90^{\circ}$ pulse was $13.8 \mu \mathrm{s}$ and the $180^{\circ}$ pulse was $27.6 \mu \mathrm{s}$. A total of 14 points were collected and the $\mathrm{d} 1$ was kept at $3 \mathrm{~s}$. 
TGA experiments were conducted on a TA instrument on fully hydrated samples. Just before the experiment, the samples were removed from water, blotted to remove the surface water and placed in the TGA sample pan. Air was the atmosphere and $10{ }^{\circ} \mathrm{C} / \mathrm{min}$ was the heating rate.

\section{Results}

\subsection{Model copolymers}

A set of partially disulfonated poly(arylene ether sulfone) copolymers based on biphenol were prepared for this research according to previously-established methods [4, 8-12]. This series of copolymers is called BPSH-xx [Fig. 1(a)], where BP stands for biphenol, $\mathrm{S}$ is for sulfonated, and $\mathrm{H}$ denotes the protonated form of the acid where $\mathrm{xx}$ represents the percentage of the units that are disulfonated. Similar to the BPSH series, hydroquinone based partially disulfonated poly(arylene ether sulfone) [HQSH-xx - Fig. 1(b)] random copolymers and partially disulfonated poly(arylene ether ketone) random copolymers [29] [B-ketone-xx - Fig. 1(c)] were also studied. Both random linear and crosslinked membranes have been investigated. In addition to the random copolymers, a series of multi-block poly(arylene ether)-b-polyimide copolymers [BPSH-x-PI-y Fig. 1(d)] was also synthesized. In the multi-block copolymers, $x$ and $y$ represent the block lengths in $\mathrm{kg} / \mathrm{mole}$ of the hydrophilic and hydrophobic segments, respectively. The IECs of the multiblock copolymers were kept similar $(1.5 \sim 1.6 \mathrm{meq} / \mathrm{g})$ as the individual molecular weights of the hydrophobic and hydrophilic blocks were varied from 5000, 10,000 to 15,000 g/mole. 


\subsection{Water uptake}

Water absorption in proton exchange membranes is considered to be one of the most important properties. On one hand, proton conductivity is a strong function of the water content of the polymer and increases with increasing water content [37]. On the other hand, low swelling in water is desired for the membrane to improve fuel cell durability. Figure (2) represents the water uptake as a function of IEC (expressed as meq/g of dry polymer) for some of the random, multi-block and Nafion ${ }^{\circledR} 117$ copolymers. A sharp increase in water uptake is observed after reaching a particular IEC for the random copolymers. Previous reports from our laboratories have related this IEC to a percolation threshold for water [12]. A morphological transition from a closed to open structure accompanies this IEC with a sharp increase in water uptake and this is supported by AFM micrographs [30].

The three multi-block copolymers had similar IECs to each other, $1.5-1.6 \mathrm{meq} / \mathrm{g}$. Studying materials with equal block lengths was appropriate for gaining understanding of the effect of block lengths on the properties of copolymers at the same ion content. A sharp increase in water uptake was associated with increasing block number average molecular weights from 5-5 to 10-10 and $15-15 \mathrm{~kg} /$ mole. For comparison, the random HQSH 30 copolymer had a similar IEC. Unlike the random copolymers where the sulfonic acid groups were randomly distributed in pairs along the chain, the multi-block copolymers featured multiple alternating sequences of hydrophilic and hydrophobic segments. Although the ionic content for the three multi-blocks was similar, the chemical incompatibility between the individual blocks resulted in better phase separation with increasing block length. AFM studies of the hydrated membranes revealed the formation of a co- 
continuous morphology with increasing block length, particularly for the BPSH-15-PI-15 [37]. The morphological transition was accompanied by a sharp increase in water absorption.

The study was conducted under fully hydrated conditions. It is also important to understand the influence of IEC and morphology on the water uptake over a wide range of water activities. Here the water activity is defined by Equation (1). To normalize the effect of IEC, water uptake for the copolymers are hereafter reported as hydration numbers. The hydration number $(\lambda)$ is defined as the number of water molecules absorbed per sulfonic acid group (Eq. 2).

$$
\begin{array}{ll}
\text { Water Activity }=\% \mathrm{RH} / 100 & \text { Equation } 1 \\
\lambda=\frac{\left(\operatorname{mass}_{\text {wet }}-\operatorname{mass}_{d r y}\right) / M W_{\mathrm{H}_{2} \mathrm{O}}}{I E C * \operatorname{mass}_{d r y}} & \text { Equation 2 }
\end{array}
$$

Figure (3a) shows the influence of water activity on water uptake for the random HQSHxx copolymers with varying IEC and Figure (3b) shows the same for the BPSH-x-PI-y multiblocks with increasing block lengths. The same data for the HQSH 30 random copolymer is also included in Figure (3b) for comparison since it has a similar IEC to the multi-block copolymers. At low water activities (i.e., low RH), the hydration numbers for all of the random copolymers were similar. This was also true for the multi-block series but the hydration numbers for the multiblock series were higher at a given water activity. At low water activity, the nature of the water tends to depend on the nature of the sulfonic acid groups and the chemical composition of the backbone. A sudden increase in hydration number after a certain water activity $(\sim 0.8)$ was observed for both the random and multi-block copolymers. This was more pronounced for random 
copolymers with higher IEC and for multi-blocks with higher block lengths. The increasing ion content in random copolymers and the increasing block lengths in the multi-block copolymers were accompanied by morphological changes within the copolymers with altered types of water. This phenomenon has been examined in depth using DSC and NMR relaxation measurements.

\subsection{DSC results}

The influence of degree of disulfonation on the melting endotherms of the freezable water in the HQSH-Xx copolymers under fully hydrated conditions after equilibration in liquid water is shown in Figure (4a). The DSC thermograms show an overlapping set of heats of fusion peaks that we attribute to free water (expected at $0{ }^{\circ} \mathrm{C}$ ) and loosely bound water from -30 to $10{ }^{\circ} \mathrm{C}$. The areas under the peaks increase with increasing degrees of disulfonation, thus suggesting the presence of increased amounts of freezable water with increasing ion content. Similar results were

obtained for the other copolymers. Studies conducted on the multi-blocks indicated a strong influence of morphology and block length on the melting endotherm peaks. In spite of having similar ion concentrations, the areas under the peaks increased with increasing block lengths as shown in Figure (4b). The supporting AFM images show the formation of a more ordered nanophase-separated morphology with increasing block length [33]. The samples were imaged under ambient conditions. Hence, in addition to ion content, the morphology of the hydrated copolymer also correlates with the freezable water content.

Besides ion content and morphology, the extent of crosslinking was also found to impact the freezable water content. Figure (4c) displays melting endotherms of the freezable water as a 
function of the curing time in the series of membranes prepared from phenol terminated oligomers crosslinked with an epoxy reagent. The area under the endotherms, which is qualitatively related to the amount of the freezable water, decreased with increased curing time. As the gel fraction was increased from 20 to $80 \%$, significant reductions in the areas under the endotherms were observed. The ratio of free to bound water decreased with increased crosslink density. Thus by crosslinking one can change the distribution of the states of water in a PEM without changing the ion content of the material.

The influence of water content on the endothermic heat of fusion peaks of the water, and glass transition temperatures ( $\mathrm{T}_{\mathrm{g}}$ 's) for the HQSH 35 and BPSH-15-PI-15 copolymers are shown in Figures (5a) and (5b). At fully hydrated conditions (equilibrated in liquid water), a sharp melting endotherm of water is observed near $0{ }^{\circ} \mathrm{C}\left(\mathrm{T}_{\mathrm{m}}\right)$. The maxima in the $\mathrm{T}_{\mathrm{m}}$ 's of the freezable water for the copolymers are provided in Table (1). The areas under the melting endotherm peaks broaden and decrease with a decrease in water content (represented within parenthesis) in the membranes for both HQSH 35 (42\%) and BPSH-15-PI-15 (56\%) copolymers. This indicates the presence of a higher fraction of loosely bound freezable water over free water at this hydration level for each of the two copolymers. However, with further decreases in water content, no endothermic peaks were observed in the DSC traces. The water at these lower hydration levels in the copolymers is non-freezable and can be correlated to the amount of tightly bound water in the membranes. The hydrated $\mathrm{T}_{\mathrm{g}}$ 's shown in Figures (5a) and (5b) for the HQSH 35 random copolymer and PBSH-15-PI-15 multi-block copolymer as a function of the amount of absorbed water emphasize the plasticization effect of water in these materials. It is noteworthy, however, that all of the $\mathrm{T}_{\mathrm{g}}$ 's in these materials are well above the $\alpha$ relaxation of 
Nafion ${ }^{\circledR}\left(\sim 80^{\circ} \mathrm{C}\right)[7]$. Thus, it is reasoned that the upper use temperatures for these disulfonated hydrocarbon polymers in a hydrated fuel cell environment should be well above that of Nafion ${ }^{\circledR}$.

In order to obtain a more accurate estimation of the tightly bound water content, as suggested by Quinn et al. [14], the integrated change in enthalpy (per gram of dry polymer) was plotted as a function of hydration number for the HQSH-xx series (Figure (6)). All of the HQSH copolymers irrespective of the degree of disulfonation showed a similar intercept, i.e., an identical non-freezable, tightly bound water content $(\lambda=8-9$ molecules of water per sulfonic acid group). As depicted in Figure ((3a), this corresponds to the water content at a relative humidity of $80-90 \%$. Thus, at equilibrium water uptakes less than those at about $80 \%$ relative humidity, the water in these random disulfonated poly(arylene ether) membranes does not freeze. Subtracting this value from the total water content gives the respective freezable and nonfreezable (tightly bound) water contents in the membranes. Similar analyses for all the copolymers were conducted.

Water, known to act as a plasticizer with a $\mathrm{T}_{\mathrm{g}}$ around $-139{ }^{\circ} \mathrm{C}$, depresses the $\mathrm{T}_{\mathrm{g}}$ 's of the copolymers. The $\mathrm{T}_{\mathrm{g}}$ 's of the copolymers measured under fully hydrated conditions are reported in Table (1). The hydrated $T_{g}$ restricts the upper use temperature for fuel cell operations. The depression in $T_{g}$ with increasing water contents in the copolymers is shown in Figures (5a) and (5b) for the HQSH 35 and the BPSH-15-PI-15 respectively. Kim et al. were able to scale this depression in $T_{g}$ more precisely with the tightly bound water content rather than with the total water content in the membranes [15]. The areas under the melting endotherms were normalized to obtain the $\Delta \mathrm{H}_{\text {fus }} / \mathrm{g}$ of the freezable water. $\Delta \mathrm{H}_{\text {fus }} / \mathrm{g}$ increased with increasing ion concentration 
for the random copolymers and with increasing block lengths for the multi-blocks. Nafion ${ }^{\circledR}$ had the highest $\Delta \mathrm{H}_{\text {fus }} / \mathrm{g}$ among the studied copolymers. Qualitatively the $\Delta \mathrm{H}_{\text {fus }} / \mathrm{g}$ can be related to the nature of the water-water interaction. A higher value represents better water-water interactions or decreased water - polymer interactions, indicating the presence of more free water concentration in the system.

\subsubsection{NMR relaxations $\left(T_{2}\right.$ and $\left.T_{1}\right)$}

In efforts to distinguish the freezable water in terms of loosely bound and free water content, $T_{2}$ NMR relaxation experiments were conducted. The mechanism for $T_{2}$ relaxation in sulfonic acid containing polymers is believed to be an exchange process between the water molecules and the exchangeable protons on the sulfonic acid groups [19]. Tightly and loosely bound water molecules associated with the sulfonic acid groups would be expected to undergo transverse relaxation faster than free water molecules that are not bound. For the copolymers studied, the $\mathrm{T}_{2}$ data could not distinguish the shortest (tightly bound) and the intermediate (loosely bound) components from each other. Loosely bound and tightly bound water are believed to exist in a hydrophilic domain wherein fast exchange can occur between the two environments relative to the measurement time of the NMR experiment. Specifically, for the copolymers having water absorption below the sharp inflection point in water uptake (the percolation threshold (see Figs. 2 and 7)), the $\mathrm{T}_{2}$ relaxation data fitted a mono-exponential decay function well (suggesting fast interchange among bound water molecules). By contrast, for the cases where the presence of free water was suggested by the DSC measurements, the $\mathrm{T}_{2}$ decay functions did not fit a monoexponential function well, and these were fitted to a bi- or tri-exponential function to estimate the 
amount of free water. $T_{2}$ values for each of those components fitted with the multi-exponential functions are shown in Table 2 for the random copolymers. For the copolymers with higher IEC's (i.e., B-ketone-50, HQSH-30 and HQSH-35), there was a substantial difference in the longer $\mathrm{T}_{2}$ component from the faster-relaxing component, and thus in those cases, this was attributed to free water. It is noted that these high IEC copolymers with the longer $\mathrm{T}_{2}$ component also had a more open or co-continuous morphology. Therefore, the appearance of the multi-exponential $\mathrm{T}_{2}$ nature in these high IEC copolymers with both random and multi-block microstructures may be a direct result of the onset of the co-continuous morphology. Thus, the free water content was estimated from NMR, and the tightly bound water was quantified from DSC measurements. Subtracting the free and tightly bound water from total water content allowed estimation of the loosely bound water. Thus NMR in conjunction with DSC experiments allowed for estimating the distributions of the states of water in the copolymers as shown in Table (3). It is recognized that migration of $\mathrm{H}_{3} \mathrm{O}^{+}$, as well as $\mathrm{H}^{+}$translation between acceptor and donor oxygens in hydrogen bonded $\mathrm{H}_{2} \mathrm{O}$ molecules may be better facilitated by liquid-like water and less so by water bound to the polymer in differing degrees. Thus, the hydration numbers $(\lambda)$ in Table 3 are reported for each state of water. This designation gives the number of water molecules in each state per sulfonic acid moiety.

The mechanism for $T_{1}$ relaxation is known to be different from $T_{2}$ relaxation [19]. $T_{1}$, the longitudinal NMR relaxation time, provides an idea of the nano-viscosity of the sulfonic acid domains that may correspond to the state(s) of water in those domains. The inverse of the $\mathrm{T}_{1}$ relaxation times $\left(1 / \mathrm{T}_{1}\right)$ can be related to the correlation time $\left(\tau_{\mathrm{c}}\right)$ for molecular motion. A high value of $1 / T_{1}$ indicates a fast exchange process and restricted molecular mobility of the water molecules. $1 / \mathrm{T}_{1}$ values for the copolymers are reported in Table (3). The water molecules associated with low IEC random copolymers have very high $1 / \mathrm{T}_{1}$ times (slow $\mathrm{T}_{1}$ relaxation). This 
fast exchange process between the water molecules and the sulfonic acid groups indicates strong water-polymer interactions and the presence of mostly bound water. At a given IEC, the poly(arylene ether ketone) copolymers have higher $1 / \mathrm{T}_{1}$ values for water in comparison to the poly(arylene ether sulfone) copolymers. This suggests that the ketone group, being more polarizable than the sulfone, interacts more with the water and more of the water is tightly bound. The $1 / T_{1}$ value decreased with increasing IEC for the random copolymers and at high IECs, the value approached a $1 / T_{1}$ similar to Nafion ${ }^{\circledR}$. The low $1 / T_{1}$ value corresponds to increased water molecular mobility or better rotational dynamics, suggesting the appearance of free and possibly loosely bound water in those copolymers. In addition to IEC, the rotational dynamics of water are also influenced by the morphology of the water-swollen copolymers. The $1 / T_{1}$ value decreased with increasing block length in the multi-block series of materials. The co-continuous hydrophobic-hydrophilic domain morphology influenced the rotational dynamics of water and would be expected to influence the translational dynamics or the diffusion coefficients of water also.

Estimation of the distributions of the three states of water was achieved using a combination of DSC and NMR relaxation measurements. Thermo-gravimetric analysis (TGA) was also employed as a complementary means to help understand the different states of water. It is clear that the rate of desorption of a molecule, in this case water vapor, from these disulfonated polysulfones as measured by the loss of volatiles by TGA should depend on the $\mathrm{T}_{\mathrm{g}}$ of the waterplasticized copolymer and also on the strength of polymer-water interaction [38]. In light of the DSC and the NMR relaxation experiments, differences in water - polymer interactions were predicted for the different states of water. Hence the retention of water as a function of temperature 
was expected to be different for different types of water. Figure (8) represents the weight loss or retention of water as a function of temperature for the HQSH-xx and Nafion ${ }^{\circledR}$ copolymers. An initial rapid loss in hydration number was observed for all of the copolymers up to 50 to $60{ }^{\circ} \mathrm{C}$. The water lost in this temperature regime was attributed to water that had the weakest interactions with the copolymer. After this temperature regime, the rate of loss of water was very slow over a wide temperature range. Hence the residual water in the membrane seems to resemble the tightly bound water content and was calculated from the ordinate value (Fig. 8). For the random copolymers, as IEC is increased free water begins to appear and this transition in structure-property relationships is attributed herein to a morphology with increased connectivity among the hydrophilic domains. The TGA data shows that as water is decreased to the point where it is nonfreezable $(\lambda=8-9)$, the remaining water diffuses out of the polymers very slowly. Thus, it may be that the morphological transition back to a less interconnected hydrophilic network also occurs as the water exits the polymers. For the HQSH-xx series and Nafion ${ }^{\circledR}$, the tightly bound water contents estimated in this manner from TGA ( 9 and 2 respectively) were consistent with the DSC and NMR results.

\section{Discussion and Conclusions}

Estimations of the contents of the three types of water in the copolymers as a function of IEC and block lengths are given in Table (3). For the random copolymers, the loosely bound and free water comprising the freezable water increased with increasing IEC. The increasing free water content influenced the thermodynamic and rotational properties of water in the PEMs. This is in agreement with the increasing $\Delta \mathrm{H}_{\text {fus }}$ and decreasing $1 / \mathrm{T}_{1}$ relaxation trends with IEC, as observed 
from the DSC and NMR measurements. It is important to note that free water only develops in the random copolymers after reaching a particular IEC. This particular IEC also corresponds to the characteristic non-linear increase in water uptake (Fig. 2).

The question arises regarding the reason behind the origination of free water in these copolymers. The random copolymers containing sulfonic acid groups phase separate into hydrophobic and hydrophilic domains with increasing IEC and water uptake [11]. At higher sulfonic acid compositions, the hydrated hydrophilic domains grow in size and interconnect with each other to form a percolated type morphology.

The multi-block copolymers had similar ion contents to each other but appeared to have better phase separation with increasing block length. With the IEC's being similar in the series, morphology was a strong function of the block lengths. Both loosely bound and free water content increase with increasing block lengths and the extent of microphase separation. The sharp increase in the area under the melting endotherm correlates with the origin of the free water inside cocontinuous ordered hydrophilic domains for the BPSH-15-PI-15 copolymer. Thus microphase separation between hydrophilic and hydrophobic domains or the connectivity between hydrophilic domains seems to be one of the major factors aligned with the origin of free water.

The tightly bound water content determined from DSC measurements depends on the nature of the sulfonic acid groups or the strength of the conjugate base and the chemical backbone. Per sulfonic acid group, Nafion ${ }^{\circledR}$ has the least amount of tightly bound water followed by the random copolymers and then the block copolymers. The chemical structure of Nafion ${ }^{\circledR}$ consists of highly flexible side chains bearing the hydrophilic sulfonic acid groups and a highly hydrophobic, fluorinated, relatively-flexible backbone. The perfluorosulfonic acid is a very strong 
acid, and its conjugate base is weak with reduced effective charge density. The weak conjugate base, the highly hydrophobic backbone, and possibly the (flexible) distance between the backbone and the sulfonic acid group, results in a lower water coordination number or precisely the tightly bound water content in Nafion ${ }^{\circledR}$.

In contrast, for the random aromatic copolymers studied herein, the sulfonic acid groups are directly attached to the main polymer chain backbone. This results in a restricted morphological structure. Also compared to $\mathrm{Nafion}^{\circledR}$, the sulfonic acid groups are of lower acidity (the conjugate base is stronger). A stronger conjugate base increases the negative charge density and hence results in more tightly bound water. The normalized tightly bound water content per sulfonic acid group was independent of the overall ion content in the copolymers.

In the multi-block copolymers, the nature of the sulfonic acid group is similar to the aromatic random copolymers studied. However, unlike the random copolymers where the sulfonic acid groups are distributed throughout the copolymer, in the multi-blocks the sulfonic acid groups are arranged in a concerted array. As a result, the local effective negative charge density is higher in the multi-blocks compared to the random copolymers. We suggest that this may be a reason for the increased tightly bound water content in the multi-blocks.

The study revealed strong relationships among the morphologies, chemical structures and compositions with the different types of water. In Part B, the distribution of these states of water in the copolymer will be related to the fundamental transport properties. The states of water 
coupled with transport property measurements will be instrumental in developing structuretransport property relationships for PEMs.

\section{Acknowledgements}

The authors would like to thank the National Science Foundation "Partnership for Innovation" Program (HER-0090556) and the Department of Energy (DE-FC36-01G01086) for support of this research effort. The authors would also like to thank Sandia National Laboratories for their support.

References:

1. Winter M and Brodd RJ. Chem Rev 2004;104(10):4245-4269.

2. Zalbowitz M and Thomas S. Fuel Cells: Green Power, Los Alamos National Laboratory Monograph LA-UR-99-3231 1999;LANL, Los Alamos, NM.

3. Carrette L, Friedrich KA, and Stimming U. ChemPhysChem 2000;1(4):162-193.

4. Hickner MA, Ghassemi H, Kim YS, Einsla BR, and McGrath JE. Chem Rev 2004;104(10):4587-4611.

5. Mauritz KA and Moore RB. Chem Rev 2004;104(10):4535-4585.

6. Yeo RS. J Electrochem Soc 1983;130(3):533-538.

7. Page KA, Cable KM, and Moore RB. Macromolecules 2005;38(15):6472-6484.

8. Wang F, Hickner M, Ji Q, Harrison W, Mecham J, Zawodzinski TA, and McGrath JE. Macromol Symp 2001;175:387-395.

9. Wang F, Hickner M, Kim YS, Zawodzinski TA, and McGrath JE. J Membr Sci 2002;197(1-2):231-242.

10. Kim YS, Sumner MJ, Harrison WL, Riffle JS, McGrath JE, and Pivovar BS. J Electrochem Soc 2004;151(12):A2150-a2156.

11. Kim YS, Hickner MA, Dong LM, Pivovar BS, and McGrath JE. J Membr Sci 2004;243(12):317-326.

12. Kim YS, Wang F, Hickner M, McCartney S, Hong YT, Harrison W, Zawodzinski TA, and McGrath JE. J Polym Sci Pol Phys 2003;41(22):2816-2828.

13. Zawodzinski TA, Neeman M, Sillerud LO, and Gottesfeld S. J Phys Chem 1991;95(15):6040-6044.

14. Quinn FX, Kampff E, Smyth G, and Mcbrierty VJ. Macromolecules 1988;21(11):31913198.

15. Kim YS, Dong LM, Hickner MA, Glass TE, Webb V, and McGrath JE. Macromolecules 2003;36(17):6281-6285.

16. Hodge RM, Edward GH, and Simon GP. Polymer 1996;37(8):1371-1376. 
17. Hodge RM, Bastow TJ, Edward GH, Simon GP, and Hill AJ. Macromolecules 1996;29(25):8137-8143.

18. Ghi PY, Hill DJT, and Whittaker AK. Biomacromolecules 2002;3(5):991-997.

19. Barbieri R, Quaglia M, Delfini M, and Brosio E. Polymer 1998;39(5):1059-1066.

20. Quinn FX, Mcbrierty VJ, Wilson AC, and Friends GD. Macromolecules 1990;23(21):4576-4581.

21. McConville P and Pope JM. Polymer 2001;42(8):3559-3568.

22. Mendil-Jakani H, Davies RJ, Dubard E, and Gebel G. J Membr Sci 2011;369(1-2):148154.

23. Pineri M, Gebel G, Davies RJ, and Diat O. J Power Sources 2007;172:587-596.

24. Perrin J-C, Lyonnard S, Guillermo A, and Levitz P. J Phys Chem B 2006;110:5439-5444.

25. Guillermo A, Gebel G, Mendil-Jakani H, and Pinton E. J Phys Chem B 2009;113:67106717.

26. Perrin J-C, Lyonnard S, Guillermo A, and Levitz P. Fuel Cells 2006;1:5-9.

27. Sankir M, Bhanu VA, Harrison WL, Ghassemi H, Wiles KB, Glass TE, Brink AE, Brink MH, and McGrath JE. J Appl Polym Sci 2006;100(6):4595-4602.

28. Li Y, Wang F, Yang J, Liu D, Roy A, Case S, Lesko J, and McGrath JE. Polymer 2006; 47:4210-4217.

29. Li YX, Mukundan T, Harrison WL, Hill M, Sankir M, Yang J, and McGrath JE. Abstracts of Papers of the American Chemical Society 2004;228:U657-U657.

30. Kim YS, Dong LM, Hickner MA, Pivovar BS, and McGrath JE. Polymer 2003;44(19):5729-5736.

31. Roy A, Hickner MA, Einsla B, Harrison WL, and McGrath JE. J Polym Sci Pol Chem 2008;47(2):384-391

32. Roy A, Hickner MA, Einsla BR, Harrison WL, and McGrath JE. J Polym Sci Pol Chem 2009;47(2):384-391.

33. Lee H-S, Badami AS, Roy A, and McGrath JE. J Polym Sci Pol Chem 2007;45(21):48794890.

34. Lee H-S, Roy A, Badami AS, and McGrath JE. Macromol Res 2007;15(2):160-166.

35. Paul M, Park HB, Freeman BD, Roy A, McGrath JE, and Riffle JS. Polymer 2008;49(9):2243-2252.

36. Sundell BJ, Jang E-S, Cook JR, Freeman BD, Riffle JS, and McGrath JE. I\&ECR 2016;55(5):1419-1426.

37. Roy A, Hickner MA, Yu X, Li Y, Glass TE, and McGrath JE. J Polym Sci Pol Phys 2006;44(16):2226-2239.

38. Encyclopedia of Polymer Science and Engineering, $2^{\text {nd }}$ Ed;1989:Supplement Volume, Mark HF, Bikales NM, Overberger CG, Menges G, and Kroschwitz JI, Eds, WileyInterscience, NY, pp 692. 
Figure 1

a)

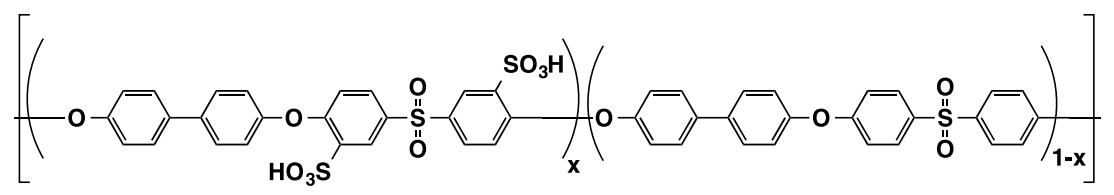

b)

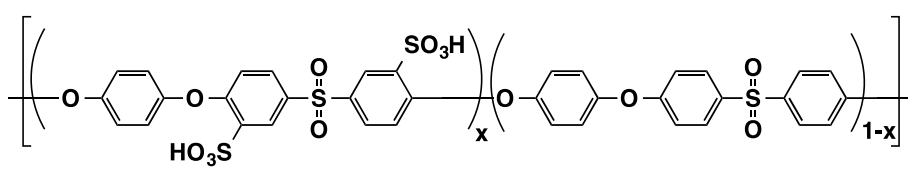

c)

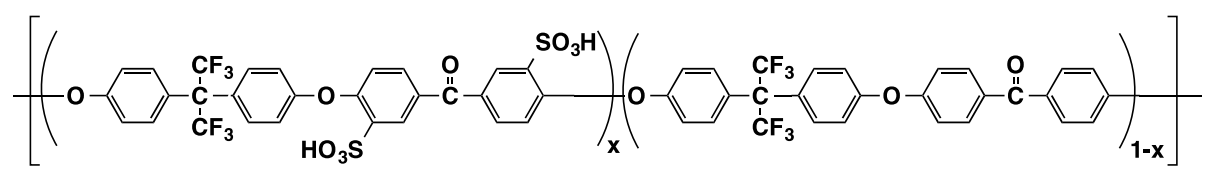

d)

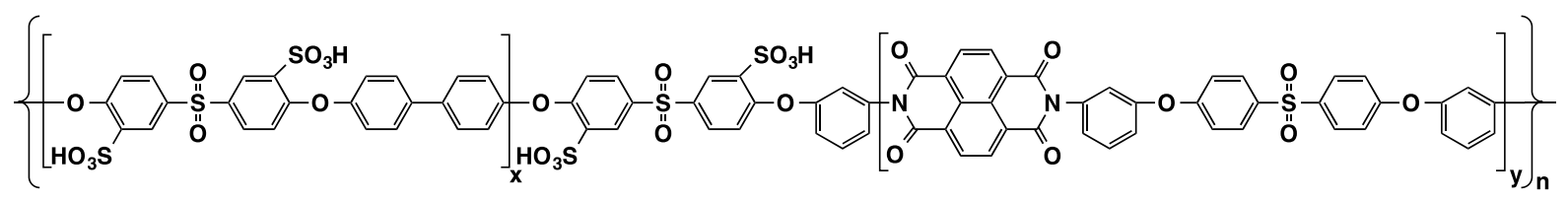


Figure 2

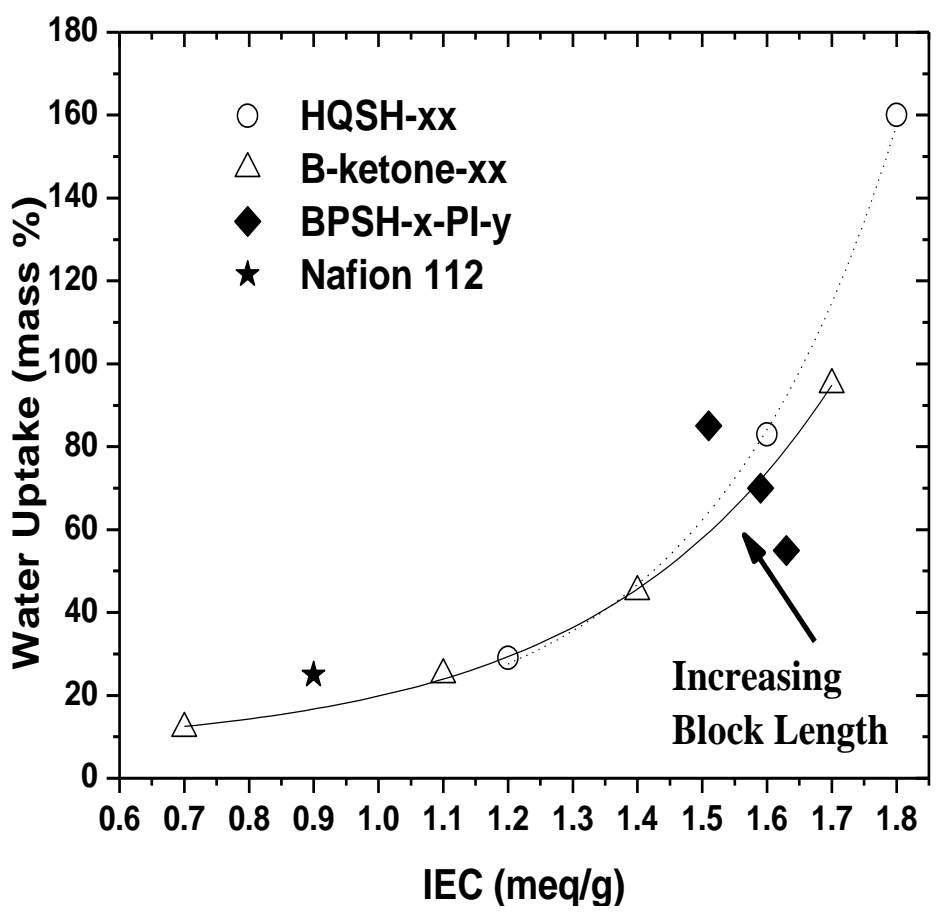


Figure 3a

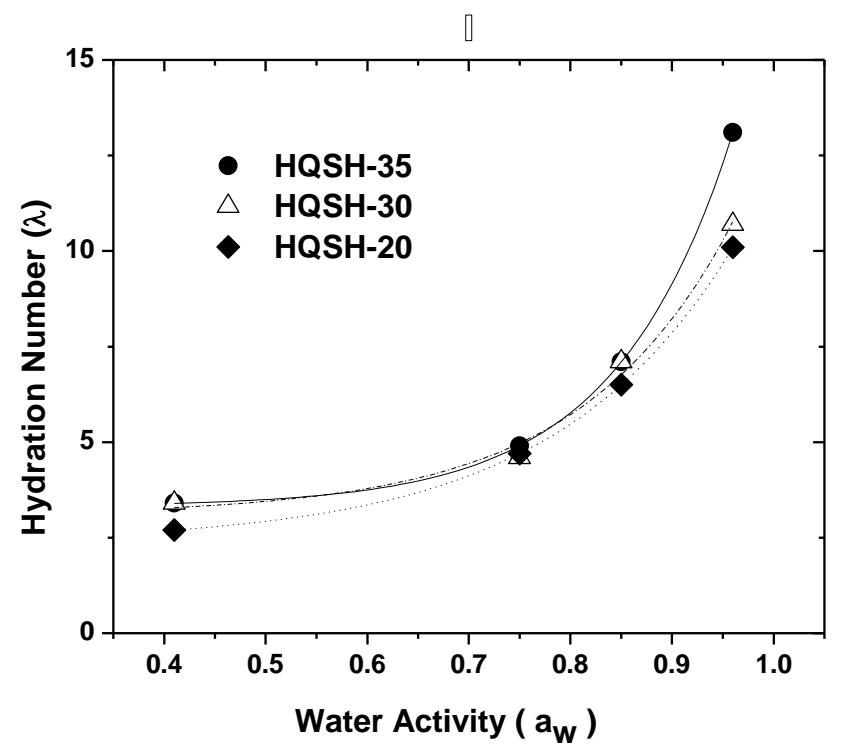


Figure $3 b$

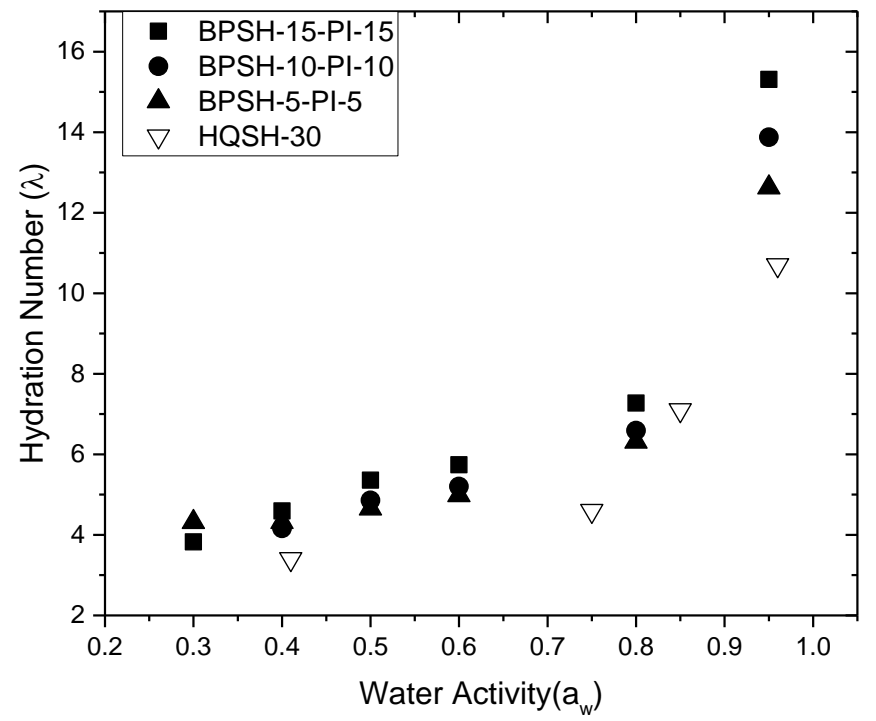


Figure $4 a$

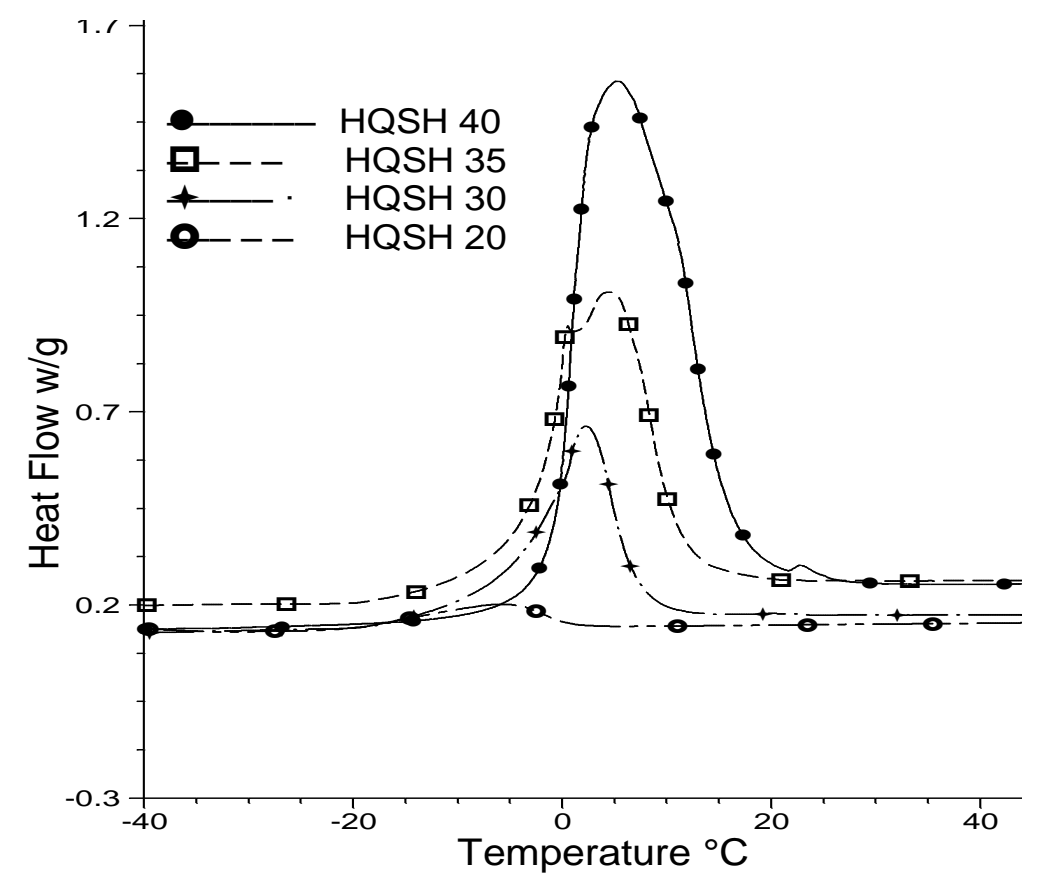


Figure 4b

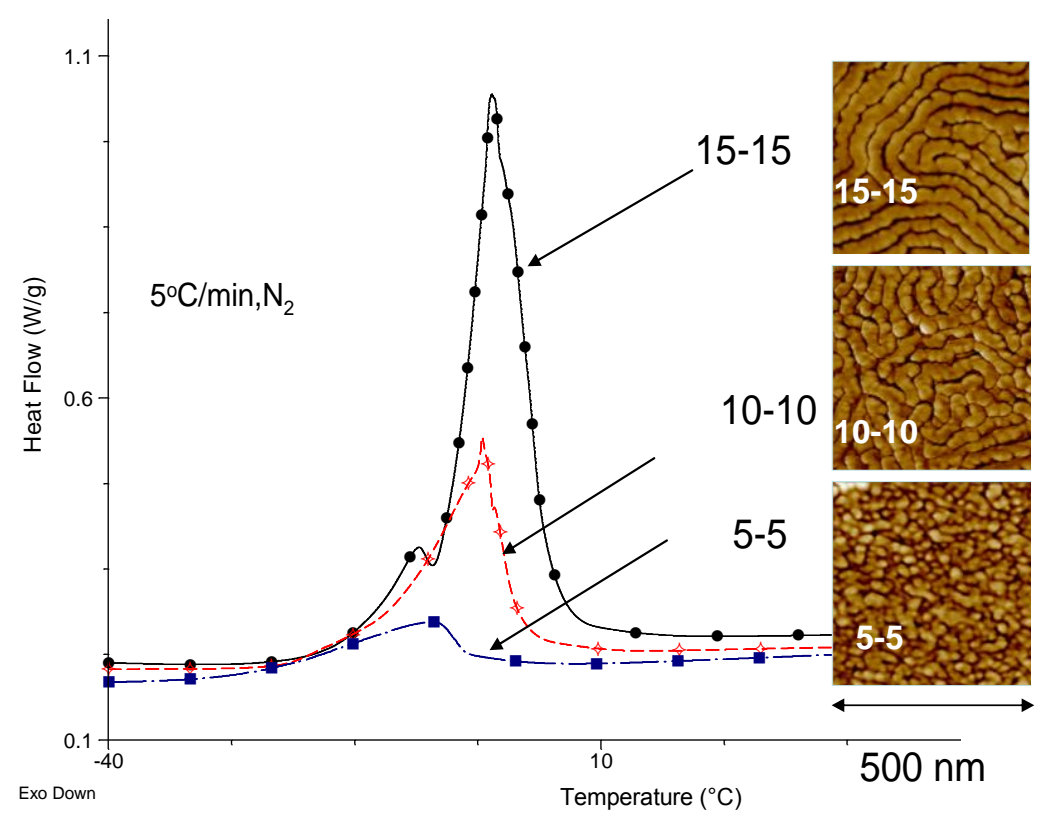


Figure 4c

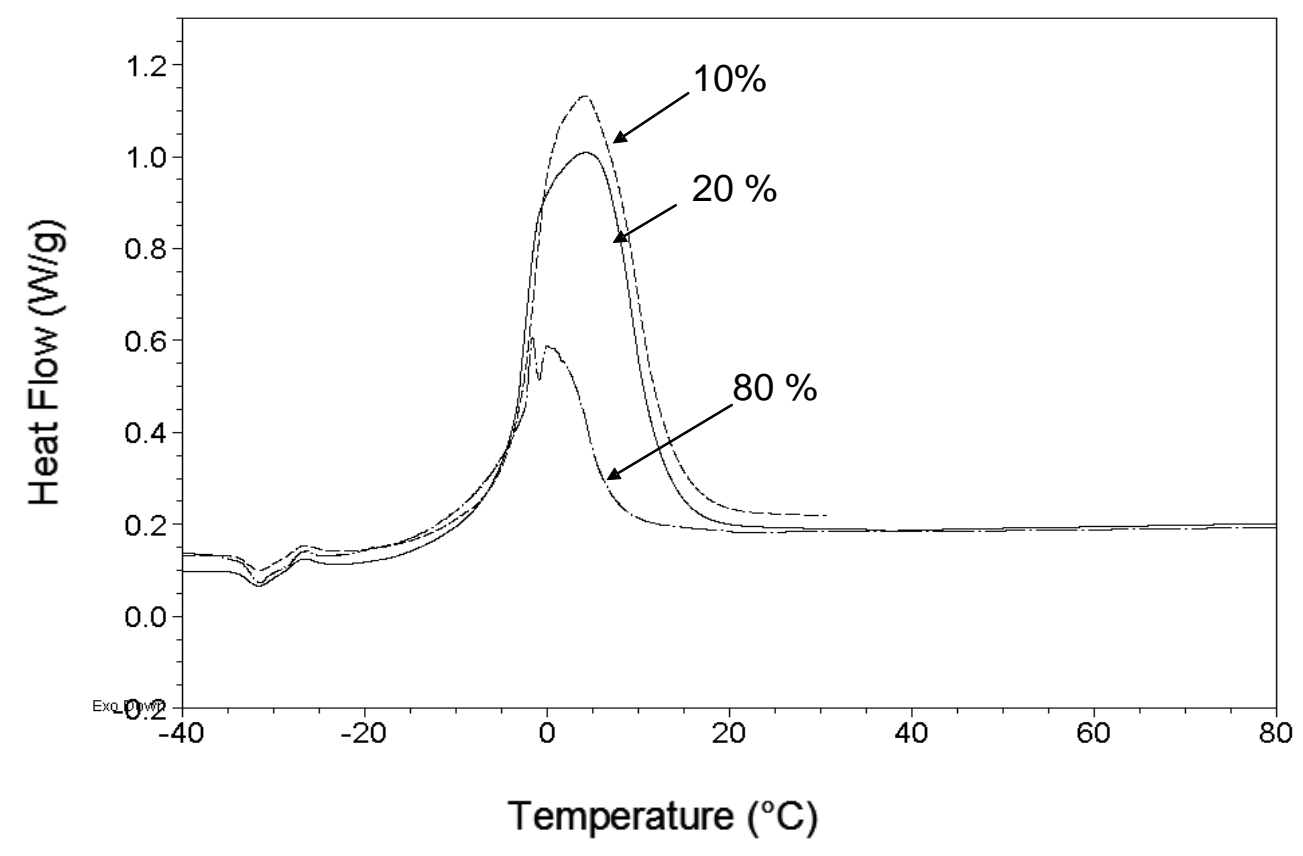


Figure 5a

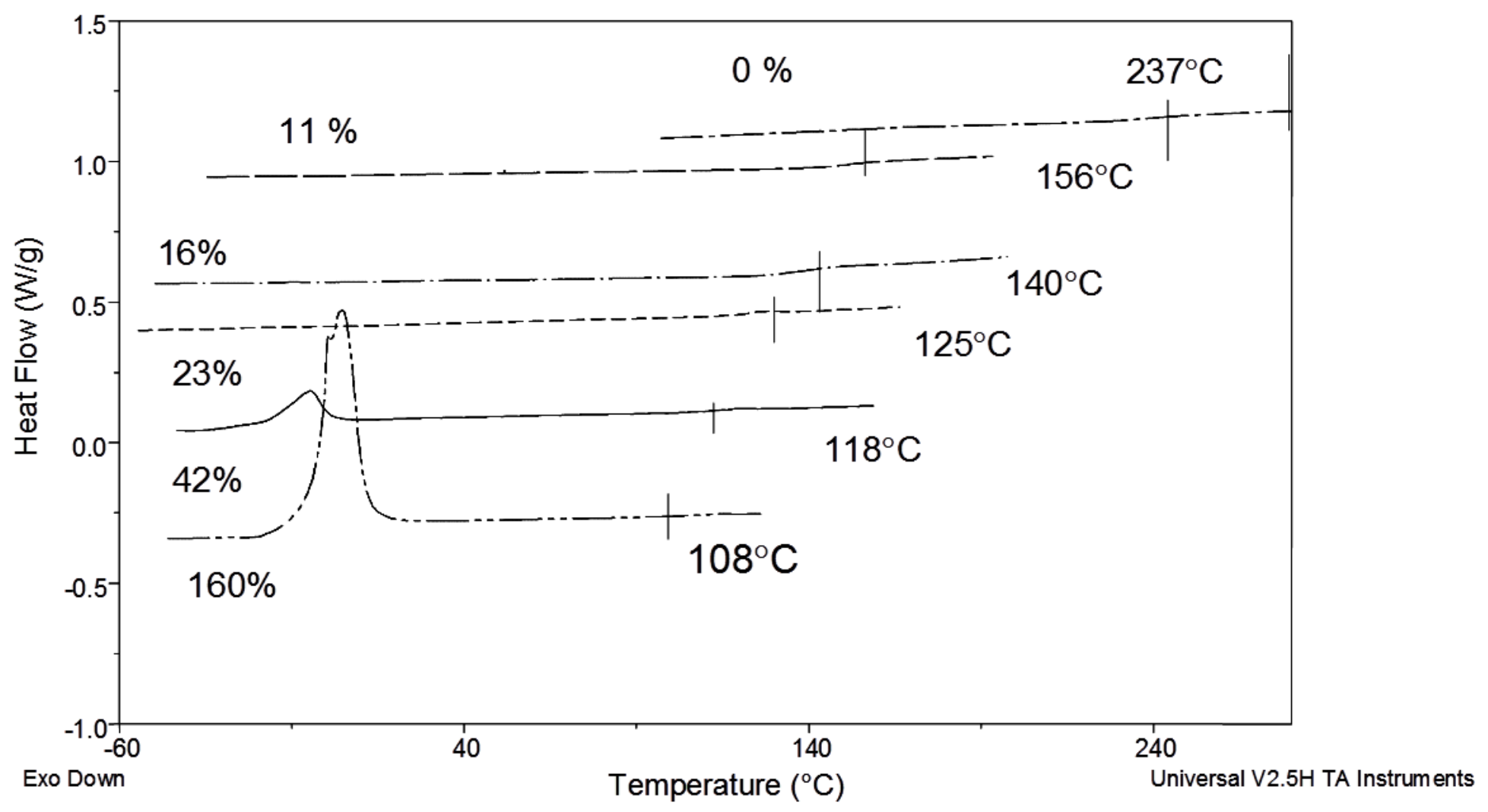


Figure 5b

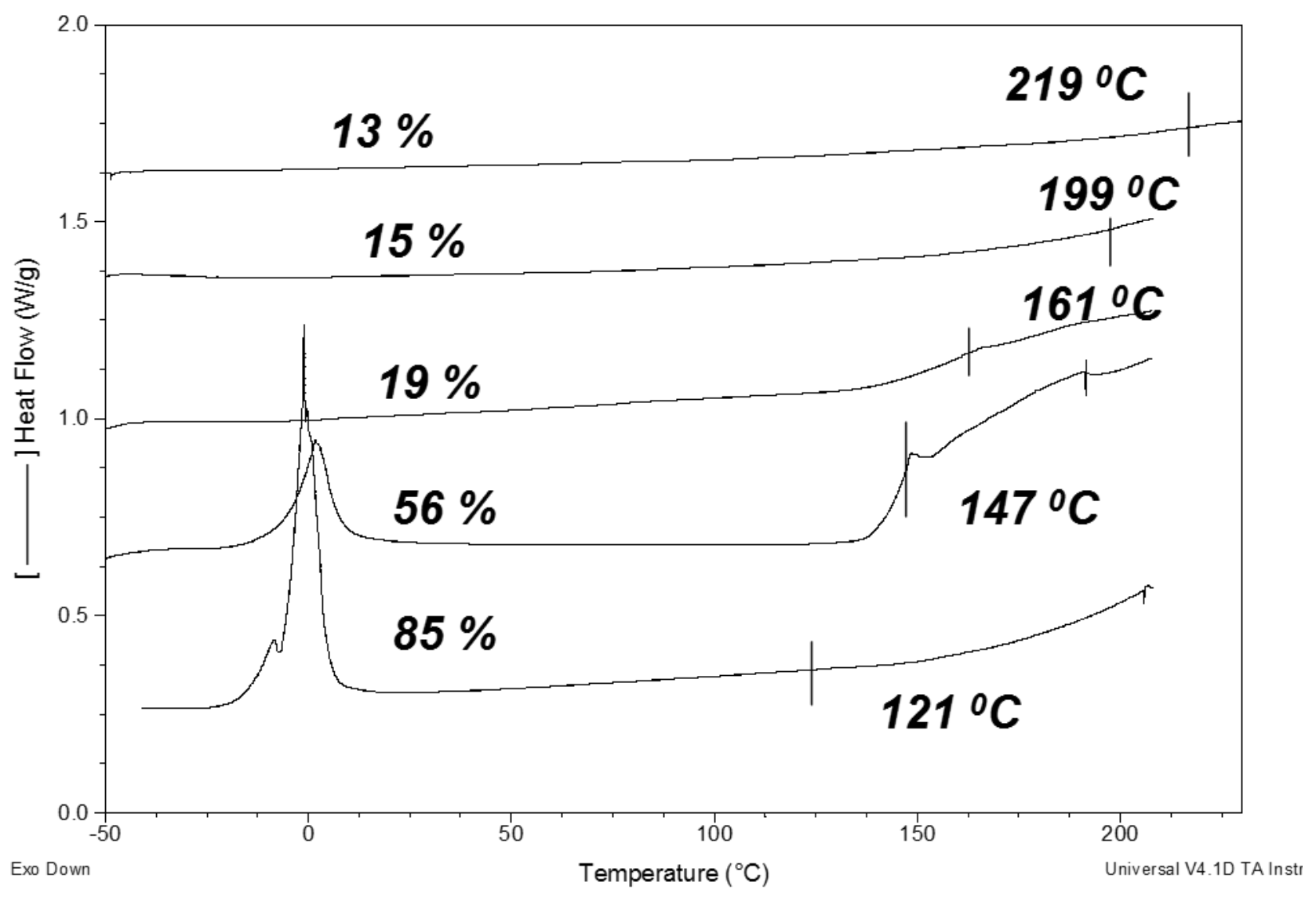


Figure 6

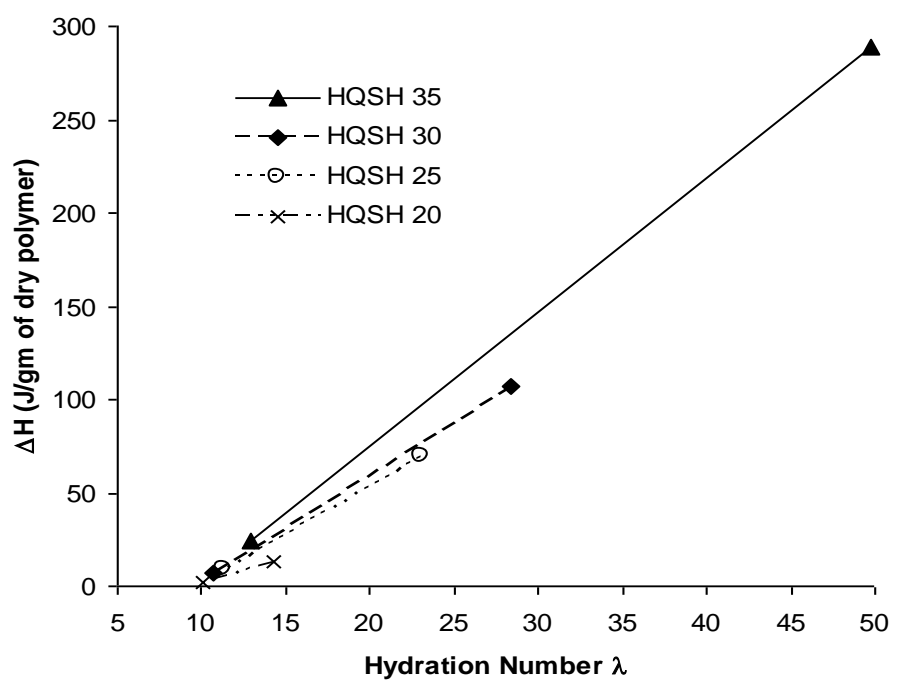


Figure 7

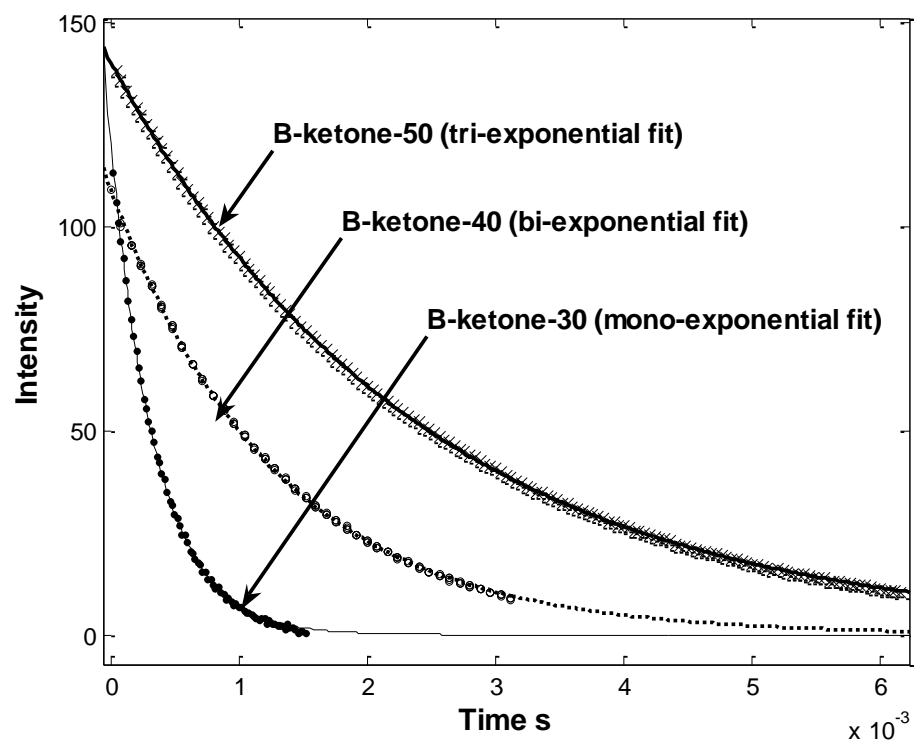


Figure 8

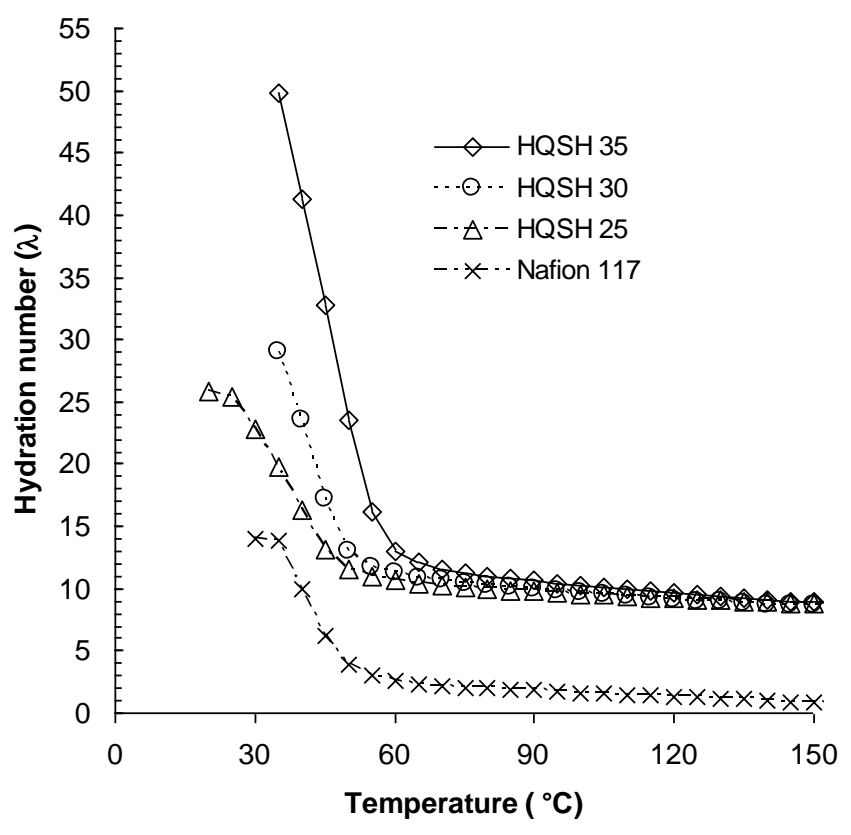


List of Figure and Table Captions

1. Figure 1 Copolymer chemical structures: (a) BPSH-xx; (b) HQSH-xx, (c) B-ketone-xx, (d) BPSH-x-PI-y multi-blocks

2. Figure 2 Influence of IEC and block lengths on water uptake at fully hydrated conditions. IEC is calculated as the milliequivalents of sulfonic acid groups per gram of dry polymer (meq/g).

3. Figure 3 a) Water absorption under partially hydrated conditions for the random HQSH$\mathrm{xx}$ copolymers as a function of IEC

4. Figure 3 b) Water absorption under partially hydrated conditions for the block copolymers BPSH-x-PI-y as a function of the block lengths. The same data for the disulfonated poly(arylene ether) HQSH 30 is also depicted for comparison since it has a similar IEC to the multi-block copolymers.

5. Figure 4 a) Melting endotherms of the freezable water in HQSH-xx copolymers as a function of degree of disulfonation under fully hydrated conditions (equilibrated in liquid water)

6. Figure 4 b) Melting endotherms of the freezable water in BPSH-x-PI-y multi-block copolymers as a function of block length under fully hydrated conditions. The numbers in the figure represent the block lengths $x-y$ respectively. Supporting AFM images are shown on the right of the figure.

7. Figure 4 c) Influence of crosslinking on the melting endotherms of freezable water in the BPSH-x-50 copolymer. The numbers in percentages represent gel fractions.

8. Figure 5 a) Influence of water content on endothermic peaks and $\mathrm{T}_{\mathrm{g}}$ 's of HQSH-35

9. Figure $5 \mathrm{~b}$ ) Influence of water content on endothermic peaks and $\mathrm{T}_{\mathrm{g}}$ 's of BPSH-15-PI-15 The numbers on the left side represent water uptake and on the right $\mathrm{T}_{\mathrm{g}}$ 's.

10. Figure 6 Normalized enthalpy changes of water as a function of the hydration number for HQSH-xx random copolymers. The intercepts are the tightly bound water contents. 
11. Figure 7 Influence of disulfonic acid concentrations on ${ }^{1} \mathrm{H} \mathrm{T}_{2}$ decays for the B-ketone-xx copolymers. The markers represent experimental data and the lines represent the fitted functions

12. Figure 8 Retention of water by thermogravimetric analyses as a function of temperature for the HQSH-xx and Nafion ${ }^{\circledR}$ copolymers 
Table 1 Summary of copolymer properties

Table 2 Estimations of $\mathrm{T}_{2}$ values from mono- and multi-exponential fits of the data for the random copolymers as a function of IEC

Table 3 Estimations of the distributions of the different states of water and $1 / \mathrm{T}_{1}$ relaxation times 
Table 1

\begin{tabular}{ccccccc}
\hline Sample & $\begin{array}{c}\text { IEC } \\
(\mathrm{meq} / \mathrm{g})\end{array}$ & $\begin{array}{c}\text { Water } \\
\text { uptake } \\
(\text { mass } \%)\end{array}$ & $\begin{array}{c}\text { Hydration } \\
\text { number }\end{array}$ & $\begin{array}{c}\Delta \mathrm{H}(\mathrm{J} / \mathrm{g} \\
\text { of }\end{array}$ & $\begin{array}{c}\text { Hydrated } \\
\mathrm{T}_{\mathrm{g}}\end{array}$ & $\begin{array}{c}\mathrm{T}_{\mathrm{m}}\left({ }^{\circ} \mathrm{C}\right) \\
\text { (fully }\end{array}$ \\
\hline Nafion 117 & 0.09 & 19 & 12 & 210 & 99 & 2.0 \\
HQSH-35 & 1.8 & 160 & 50 & 180 & 108 & 4.6 \\
HQSH-30 & 1.6 & 83 & 29 & 128 & 107 & 2.2 \\
HQSH-25 & 1.4 & 60 & 23 & 110 & 107 & 1.9 \\
HQSH-20 & 1.2 & 29 & 14 & 45 & 110 & -6.0 \\
B-ketone-50 & 1.7 & 95 & 32 & 120 & 104 & 3.3 \\
B-ketone-40 & 1.4 & 45 & 18 & 90 & 118 & 1.1 \\
B-ketone-30 & 1.1 & 25 & 13 & 5 & 99 & -1.4 \\
BPSH-5-PI-5 & 1.6 & 55 & 18 & 33 & 110 & -10.0 \\
BPSH-10-PI-10 & 1.6 & 70 & 24 & 81 & 118 & 1.0 \\
BPSH-15-PI-15 & 1.5 & 85 & 31 & 172 & 121 & 2.0 \\
\hline
\end{tabular}


Table 2

\begin{tabular}{ccccc}
\hline & & \multicolumn{3}{c}{$\mathrm{T}_{2}(\mathrm{~s})$} \\
\cline { 3 - 5 } Copolymer & IEC & Tightly & Loosely & Free \\
& $(\mathrm{meq} / \mathrm{g})$ & $\begin{array}{c}\text { Bound } \\
\text { bound }\end{array}$ & \\
& & $(\mathrm{s})$ & $(\mathrm{s})$ & $(\mathrm{s})$ \\
\hline HQSH-35 & 1.8 & 0.008 & 0.011 & 0.11 \\
HQSH-30 & 1.6 & 0.006 & 0.04 & 0.14 \\
HQSH-25 & 1.4 & 0.0017 & 0.0017 & 0.07 \\
B-ketone-50 & 2.1 & 0.0023 & 0.0023 & 0.1176 \\
B-ketone-40 & 1.7 & 0.0012 & 0.0012 & 0.0017 \\
B-ketone-30 & 1.3 & 0.0003 & 0.0003 & 0 \\
\hline
\end{tabular}


Table 3

\begin{tabular}{ccccccc}
\hline & & & Non & \multicolumn{2}{c}{ Freezing water } & \\
\cline { 5 - 6 } Copolymer & IEC & Total & freezing & Loosely & $1 / \mathrm{T}_{1}$ \\
& $(\mathrm{meq} / \mathrm{g})$ & water $(\lambda)$ & water & Found & $(\lambda)$ & $\left(\mathrm{s}^{-1}\right)$ \\
Nafion 117 & 0.9 & 17 & 3 & 9 & 5 & 4.7 \\
HQSH-35 & 1.8 & 50 & 9 & 27 & 14 & 3.6 \\
HQSH-30 & 1.6 & 29 & 9 & 11 & 8 & 6.6 \\
HQSH-25 & 1.4 & 23 & 9 & 10 & 4 & 47.6 \\
HQSH-20 & 1.2 & 14 & 9 & 5 & 0 & - \\
B-ketone-50 & 2.1 & 32 & 8 & 21 & 3 & 95.2 \\
B-ketone-40 & 1.7 & 18 & 8 & 10 & 0 & 250.0 \\
B-ketone-30 & 1.3 & 13 & 8 & 5 & 0 & 333.3 \\
BPSH-5-PI-5 & 1.6 & 18 & 14 & 4 & 0 & 166.0 \\
BPSH-10-PI-10 & 1.6 & 24 & 14 & 8 & 2 & 111.0 \\
BPSH-15-PI-15 & 1.5 & 31 & 15 & 11 & 5 & 25.0 \\
\hline
\end{tabular}


a)

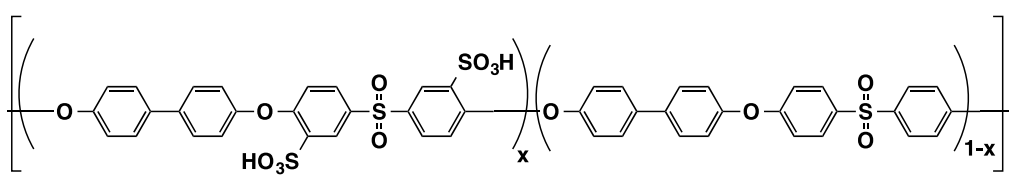

b)

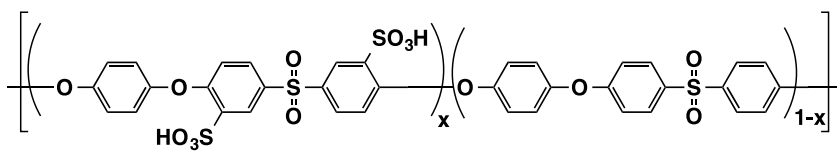

c)

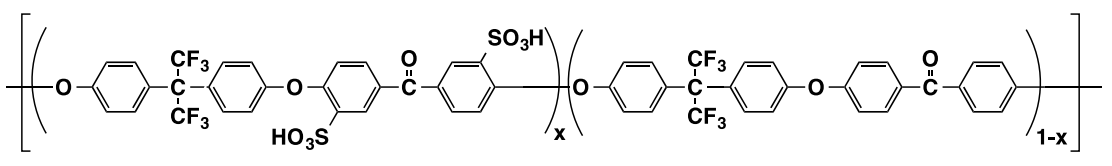

d) \{ 